\title{
EXPRESSÃO E MOVIMENTO \& CONTAÇÃO DE HISTÓRIAS NA FORMAÇÃO CONTINUADA DE PROFESSORES NO VALE DO ITAJAÍ/SC
}

\section{EXPRESSION AND MOVEMENT \& STORYTELLING IN THE CONTINUING EDUCATION OF TEACHERS IN VALE DO ITAJAÍ / SC}

\section{Ivana Vitória Deeke Fuhrmann}

\author{
Mestre em Educação pela Universidade Regional de Blumenau \\ Especialista em Movimento Humano e Saúde pela Universidade Regional de Blumenau \\ Graduada em Bacharelado e Licenciatura em Dança pela Pontifícia Universidade Católica do Paraná \\ Professora titular do Departamento de Artes da Universidade Regional de Blumenau \\ E-mail: ivacontemporaneo@hotmail.com
}

\section{RESUMO}

O estudo apresenta como objetivo efetuar um trabalho de mediação cênica a fim de garantir a qualificação de processos de ensino e aprendizagem em artes cênicas por meio de oficinas de jogos teatrais, dança e movimento, ofertadas aos professores de Educação Infantil e Básica vinculados às Secretarias de Educação conveniadas com o Programa Institucional Arte na Escola (PIAE), polo FURB- Blumenau/SC. Assim sendo, o locus de investigação foi o projeto de extensão universitária "O jogo teatral na escola", vinculado ao PIAE. O referido projeto iniciou em 2011 e oferece formação continuada. $\mathrm{O}$ artigo traz à cena a trajetória percorrida e resultados alcançados entre 2011 e 2016 onde foram oferecidas oficinas de jogos teatrais, identidade corporal, percussão corporal, movimento e ritmo e contação de histórias. Como recorte principal, encontram-se depoimentos dos professores de Educação Infantil e Básica que participaram das oficinas em 2016/1 intitulada "Movimento e Expressividade na Contação de Histórias". Tal atividade atingiu público direto de 82 professores de Indaial e Jaraguá do Sul e um público indireto de 4.723 composto pelos alunos dos professores que cursaram as oficinas. Foram trabalhados os benefícios do movimento na qualidade de vida de professores e alunos, o gesto cênico, criação e elaboração de cenas na contação de histórias, exercícios de ação e reação. Tais dinâmicas possibilitam a democratização da cultura e viabilizam o acesso a bens simbólicos, bem como, proporcionam ampliar o conhecimento da linguagem cênica de professores e alunos. Os instrumentos de avaliação das ações do projeto foram efetuados através de protocolos, relatórios lúdicos, depoimentos orais e escritos, bem como, descrição de sensações. A avaliação investiga o alcance dos objetivos e de que maneira as atividades pedagógicas realizadas podem refletir na prática docente do participante. Amparados no referencial teórico de Spolin, Bourdieu 
e Marques os dados indicam a ampliação do repertório artístico/cultural, estimulo à interdisciplinaridade desenvolvendo um maior conhecimento corporal e do espaço cênico que por sua vez reflete positivamente na práxis pedagógica do professor.

Palavras-chave: Movimento. Expressividade. Dança. Teatro. Jogos Teatrais.

\section{ABSTRACT}

The main topic of this research is the study on the continuing education offered to Kindergarden and Basic Education teachers linked to the Educational Department ensured by the Programa Institucional Arte na Escola (PIAE), in FURB - Blumenau/SC, as objective to make a scenic mediation work to ensure the qualification of teaching and learning processes in the performing arts through theatrical games workshops, dance and movement. The locus of investigation was the university extension project "O Jogo Teatral na Escola" linked to PIAE. This project has begun in 2011 and it offers continuing education. The article brings into contention the performed trajectory and the results achieved between the years of 2011 and 2016 when workshops about theatre games, body identity, body percussion, rhythm and movement and storytelling were offered. Testimonies about Rhythm and Movement workshops made by Kindergarten and Basic Education Teachers in 2016/1, entitled "Movimento e Expressividade na Contação de Histórias" are highlighted. This activity reached a direct audience of 82 teachers of Indaial and Jaragua do Sul and an indirect audience of 4.723 composed by the students of the teachers who attended the workshops. The benefits of movement in the quality of life of teachers and students were worked on this activity as well as the scenic gesture, creation and development of scenes in storytelling, action and reaction exercises. Such dynamics allow the democratization of culture and enable access to symbolic goods, therefore, increasing knowledge of teachers and student's scenic language. Assessment tools of the project actions were made through protocols, ludic reports, oral and written testimonies as well as the description of sensations. The evaluation investigates the goal attainments and how the performed educational activities can reflect on the teaching practice of the participant. Supported by the theoretical framework of Spolin, Bourdieu and Marques, the data indicates the expansion of artistic and cultural repertoire of participants stimulating the interdisciplinarity and developing a greater body and scenic knowledge which in turn reflects positively on the teacher's pedagogic practice.

Keywords: Movement. Expressivity. Dance. Theater. Theatrical Games. 


\section{INTRODUÇÃO}

O estudo apresenta a trajetória do trabalho de formação continuada efetuado com professores da Educação Infantil e Básica da rede de ensino estadual e municipal no Vale do Itajaí/SC no período de 2011/2016 desenvolvido incluso ao projeto intitulado “O jogo teatral na escola" - vinculado ao Programa Institucional Arte na Escola (PIAE) - Polo Universidade Regional de Blumenau (FURB). Como recorte principal, em foco as oficinas ministradas em 2016/1, "Movimento e Expressividade na Contação de Histórias”. Tal atividade atingiu público direto de 82 professores de Indaial e Jaraguá do Sul e um público indireto de 4.723 composto pelos alunos dos professores que cursaram as oficinas.

Para uma compreensão mais ampla do trabalho desenvolvido aborda-se sobre o campo em questão. O PIAE é uma associação civil sem fins lucrativos que, desde 1989, qualifica, incentiva e reconhece o ensino da arte, por meio da formação continuada de professores da Educação Básica. Tem como premissa que a arte deve desenvolver habilidades perceptivas, capacidade reflexiva e incentivar a formação de uma consciência crítica. Na FURB o programa iniciou em 1993, coordenado pelas professoras Ma.Marilene de Lima Körting Schramm e Ma. Rozenei Maria Wilvert Cabral e atualmente conta com três projetos: "O jogo teatral na escola", "Formação Continuada"1 e "Midiateca"2 e vários professores envolvidos: Ma. Lindamir Aparecida Rosa Junge, Ma. Melita Bona, Ma. Rozenei Maria Wilvert Cabral e a autora deste estudo. Segundo Schramm e Cabral (2010, p. 19), a finalidade do PIAE “[...] é de fomentar a qualificação de processos educacionais em arte, com o propósito de ser agente de transformação e fonte de referência no ensino da arte, auxiliando professores, estudantes e demais interessados na área".

O PIAE tem atendido diversas cidades de Santa Catarina com os três projetos que desenvolve. O público alvo é composto especialmente por professores que trabalham na Educação Infantil e Básica, alunos da FURB (graduação e ETEVI/ensino médio da FURB) e grupos de extensão da FURB. Assim sendo, oferece oficinas e/ou palestras para professores das cidades de Blumenau, Gaspar, Indaial e Schroeder.

Nomeadamente o projeto "O jogo teatral na escola" iniciou em 2011 coordenado inicialmente pela professora Ma. Olívia Camboin Romano e a partir de 2014 pela autora deste escrito. Com o eixo inicial centrado na mediação teatral ampliou sua abrangência também para a dança e o movimento uma vez que foi identificada a carência de professores habilitados para atuarem na disciplina de Artes e, especialmente, com as áreas de dança e teatro. 


\section{O PROJETO E O “ANDAR DA CARRUAGEM" EM PROPOSIÇÕES E NÚMEROS NO PERÍODO DE 2011/2015}

Nos primeiros três anos de realização do projeto, entre 2011 e 2014, foram ofertadas oficinas de jogos teatrais e improvisação de curta duração para professores de Blumenau, Gaspar, Indaial e Schroeder e para estudantes do Ensino Médio de Blumenau. A maior parte das oficinas foram ministradas nas dependências do Curso de Teatro do Departamento de Artes da FURB; mas algumas oficinas com professores de Educação Infantil foram realizadas na cidade de Gaspar/SC.

Em 2011 foram atingidas diretamente 202 pessoas, dentre elas 74 professoras da Educação Básica, e indiretamente cerca de 3.784 pessoas. Em 2012 foram atingidas diretamente cerca de 488 pessoas, dentre elas 250, vinculadas à Educação Básica do setor público (municipal estadual ou federal), e indiretamente aproximadamente 12.102 pessoas. Em 2013 foram atingidas diretamente 218 pessoas, dentre as quais 135 são professores da rede pública de ensino, e indiretamente cerca de 9.997 pessoas. Para a quantificação foi considerado público direto os participantes das oficinas e/ou espectadores presentes nas apresentações públicas (fruto das oficinas de longa duração). $\mathrm{O}$ público indireto foi considerado os atingidos pelos desdobramentos do projeto, ou seja, os alunos dos professores participantes das oficinas.

De 2011 a 2014, as oficinas abordaram, em linhas gerais, os elementos básicos da linguagem teatral; o conceito e a prática dos "jogos teatrais"; a importância da brincadeira, do prazer aliado ao conhecimento no ensino do teatro na escola; e a elaboração de protocolos de avaliação como instrumento de avaliação das atividades.

A partir de 2014 a dança começou a integrar o conteúdo das oficinas ministradas oferecendo atividades de "Identidade Corporal" e "Percussão Corporal". Foi oportunizado aos participantes, no papel de "professores alunos", vivencias por intermédio do movimento para que criassem relações com sua própria identidade corporal e sons promovidos com o próprio corpo e desenvolvessem consciência corporal. A forma como cada qual utiliza o seu corpo diz muito do caráter, da emoção, sensibilidade, tabus constituindo a identidade. E tais experiências vivenciadas pelos professores podem posteriormente ser trabalhadas com as crianças - seus alunos.

Assim sendo, foi aliado ao trabalho já desenvolvido atividades de dança dentro do mesmo espírito de "jogos teatrais" - pautados no trabalho da diretora norte-americana Viola Spolin (1906-1994) uma vez que,

A técnica de Jogos Teatrais propõe uma aprendizagem não verbal, onde o aluno reúne os seus próprios dados, a partir de uma experimentação direta. Através do processo de solução de problemas, ele conquista o conhecimento da matéria (KOUDELA, 1998, p. 64). 
O público alvo das oficinas de "Identidade Corporal" foram 50 professoras de Educação Infantil da cidade de Indaial/SC e no caso da "Percussão Corporal" as atividades foram desenvolvidas com 23 professoras da cidade de Indaial/SC. Com a oficina de "Identidade Corporal" foi atingido um público indireto de 1.019 pessoas e na oficina de "Percussão Corporal" foi atingido um público indireto de 1.841. Assim sendo, o público total atingido foi de 2.959 pessoas. As oficinas tiveram como objetivo capacitar, de maneira inicial, tais professoras para mediarem o contato de seus alunos com as artes cênicas e neste caso em especial, com o movimento, tendo a dança como ferramenta de trabalho.

Em 2015 foram ministradas oficinas de "Movimento e Ritmo" oportunizando assim a formação continuada tendo o movimento como foco. As atividades foram desenvolvidas com 54 professoras da cidade de Indaial/SC e o público indireto totalizou 2.443. O objetivo foi trabalhar o alongamento e consciência corporal, passos de dança de variados ritmos, jogos rítmicos com elementos cênicos onde foi utilizado pedaços de "tule", jogos de ação e reação, bem como exercícios de respiração.

Em todas as oficinas os exercícios de início eram mais formais onde o aluno segue o exemplo do professor. Na sequência foram evoluindo e criações coletivas iam surgindo de forma que a improvisação passou a se fazer presente. Segundo Ryngaert (2009, p. 90-91), a improvisação “[...] provoca o sujeito a reagir, seja no interior da proposta que lhe é feita, seja em torno da proposta, explorando amplamente a zona que se desenha para ele, segundo o modo como sua imaginação é convocada".

Faz-se necessário mencionar que o "reconhecimento da arte como área de conhecimento a ser trabalhada nas escolas foi legalmente introduzido pela LDB (Lei de Diretrizes e Bases) 9394/96, em 1997, e esse processo foi coroado em âmbito nacional com a inclusão da dança nos Parâmetros Curriculares Nacionais (PCNs)"'(MARQUES, 2006, p. 101). No entanto, essa não é a prática realizada na maioria das escolas do estado de Santa Catarina e vale mencionar que o estado ainda não possui nenhuma graduação em Dança.

Assim sendo, a dança, o movimento corporal, é bastante distante dos alunos bem como dos próprios professores uma vez que não apresentam qualificação para tal e não vivenciarem referida realidade mesmo quando alunos. Marques (2006) desenvolve seus estudos abordando e defendendo a inclusão da dança na escola de ensino formal. No entanto, pondera sobre as dificuldades de incluir a disciplina dança no currículo obrigatório, afirmando que, atualmente, os professores da referida disciplina nas escolas não possuem a qualificação necessária para tal. 
Tal situação torna-se ainda mais urgente com a elaboração da Base Nacional Comum Curricular que está sendo preparada para vigorar nos próximos anos e que indica para o componente curricular Arte, no ensino formal, conteúdo de Dança, Música, Artes Visuais e Teatro com profissionais habilitados em cada linguagem. Sugere-se a construção do conhecimento em Arte amparado nas seis dimensões à saber: "criação", "crítica', "estesia", “expressão", "fruição" e "reflexão". Tais dimensões devem ser trabalhadas sem hierarquia entre elas e para tal faz-se tangente a preparação dos professores.

O tema do componente curricular Arte e a forma de sua condução dentro da escola, considerando as indicações da Base Nacional Curricular Comum, foi amplamente abordado e discutido no $4^{\circ}$ Encontro Regional Sul do Arte na Escola que ocorreu de 17 a 19 de agosto de 2016 na FURB reunindo especialmente os polos da região Sul do PIAE. Nos depoimentos de todos os grupos de trabalho ficou transparente a preocupação com a formação dos professores.

Concomitante, percebe-se que os professores que frequentam as oficinas do projeto " $\mathrm{O}$ jogo teatral na escola" são carentes de qualificação na área de artes cênicas. Por intermédio de questionários foram interrogados sobre qual a sua relação com as Artes Cênicas e às respostas demonstraram que a adesão às práticas culturais é bastante limitada e dessa forma concorda-se com Pierre Bourdieu e Alain Darbel (2003), que no livro “Amor pela Arte”, esclarecem que a cultura não é um privilégio natural e de que a prática cultural não é um dom ou uma questão de sensibilidade inata ligada à emoção, pois existem condições sociais que tornam possível o usufruto desse privilégio. Dessa forma, entende-se que por vezes as pessoas não dançam ou não compreendem seu corpo, pelo fato de tal questão não fazer parte do seu estilo de vida, de sua cultura familiar e local. Vale lembrar que Santa Catarina está localizada na região sul do Brasil, colonizada em sua maioria por europeus e assim sendo é uma região um tanto mais séria e formal e tal fato reflete no estilo de vida de seus habitantes.

Para Bourdieu (2004, p. 218-219), “[...] uma prática corporal [...] [se aprende], por uma comunicação silenciosa, prática, corpo a corpo". Assim, a disposição para a dança não é incorporada de forma mecânica, constitui-se, porém o resultado da ação sistematizada de incutir princípios coerentes, que acontece no âmbito da prática para a prática. Professores recebendo formação para apresentarem para seus alunos o que "O jogo teatral na escola" pode oferecer.

Por tais questões enfatiza-se a necessidade do então "professor aluno" vivenciar o movimento corporal e não apenas ir para a oficina e ouvir o que pode ser feito com o seu aluno em sala de aula, mas realmente fazer, "sentir na pele" para posteriormente adaptar as atividades para sua realidade em sala de aula. Ainda segundo Bourdieu (1998, p. 74 - 75 - grifos do autor), todo esse processo, 
[...] exige uma incorporação que, enquanto pressupõe um trabalho de inculcação e de assimilação, custa tempo que deve ser investido pessoalmente pelo investidor, [...] essa incorporação não pode efetuar-se por procuração. Sendo pessoal, o trabalho de aquisição é um trabalho do "sujeito" sobre si mesmo [...] Esse capital "pessoal" não pode ser transmitido instantaneamente (diferentemente do dinheiro, do título de propriedade ou mesmo do título de nobreza) por doação ou transmissão hereditária, por compra ou troca.

A dança exige entrega e o desenvolvimento da habilidade está vinculado à prática da atividade e pode oferecer grandes descobertas. Segundo Marques (2006, p.134), “a dança experimentada concretamente possibilita uma ampliação do vocabulário corporal que pode também permitir uma outra forma de se apropriarem de seus corpos, de estarem no mundo e de se comunicarem com ele".

Destarte, a dança soma-se ao contexto dos jogos teatrais e oferece a possibilidade de desdobramentos acerca da cultura local e global oferecendo um entendimento da construção da identidade corporal do cidadão. Assim concorda-se com Bourdieu (2004), que o agente social está imbricado com o estilo de vida, porque é produto de um operador prático, o habitus. Considera-se o habitus, definido por Bourdieu (2004, p. 26), como "[...] um sistema de esquemas [disposições] adquiridos que funciona no nível prático como categorias de percepção e apreciação, ou como princípios de classificação e simultaneamente como princípios organizadores da ação".

Dessa maneira os princípios organizadores da ação se estabelecem de uma forma mais ampla e profunda possibilitando maior conhecimento do corpo e consequentemente da construção corporal. Tal processo exige determinação e é atingido por intermédio da formação continuada oferecida pelas oficinas do projeto que os professores frequentam ao longo dos anos. Os depoimentos dos participantes revelam que as dinâmicas passam a interagir na sua prática docente onde os conteúdos são transpostos para a sala de aula em sua prática como professor.

\section{OS DEPOIMENTOS DOS PROFESSORES NA OFICINA "MOVIMENTO E EXPRESSIVIDADE NA CONTAÇÃO DE HISTÓRIAS"}

Em 2016/1 foram oferecidas oficinas que aliassem o movimento e a expressão. As atividades buscaram desenvolver os benefícios do movimento na qualidade de vida dos professores e posteriormente de seus alunos, a compreensão do gesto cênico, exercícios de ação e reação, criação e elaboração de cenas na contação de histórias, bem como, apresentação de cenas. Tal atividade atingiu público direto de 82 professores de Indaial e Jaraguá do Sul e um público indireto de 4.723 composto pelos alunos dos professores que cursaram as oficinas. 
Na sequencia seguem alguns fragmentos de depoimentos dos participantes: "Aproveitei cada momento da formação, pude perceber o quanto o movimento é importante no nosso dia-adia com as crianças. Tenho uma visão bem diferente a partir de hoje e vou utilizar o que aprendi aqui todos os dias, e sempre buscar coisas novas para mostrar para as crianças"; "Foi muito relaxante pra mim. Os movimentos são importantes para nossa prática enquanto professora e principalmente para o trabalho com as crianças pequenas. A expressão do corpo fala!"; "Proveitoso, atividades que podemos fazer com as crianças, passar adiante. Gostei da atividade das histórias em poucos movimentos"; "Uma tarde muito prazerosa onde pude ter várias aprendizagens e ideias das quais poderei colocar em prática na sala de aula"; "Foi uma tarde muito proveitosa, onde podemos tirar proveito para nós como pessoas e para a sala de aula com os alunos".

Percebemos que as atividades propostas incentivaram os professores envolvidos servindo para alavancar a inserção do movimento nas atividades diárias dos mesmos junto as suas atividades de trabalho, bem como, proporcionaram um maior conhecimento sobre o corpo dos mesmos.

As atividades transcorreram de forma crescente onde os professores no então papel de "alunos" foram convidados a alongar o corpo, sentir e conhecer a respiração, perceber o espaço físico e seu próprio corpo no espaço, escutar e sentir a música, criar relações com os outros, improvisar, compor histórias possuindo como ferramenta apenas o corpo sem a utilização da voz.

O movimento de início é algo que o professor no papel de então "aluno", não está habituado a praticar. Várias ações geram timidez nos envolvidos que vão sendo desmistificadas com o desenrolar da oficina como se percebe: "Esta oficina nos proporcionou momentos ricos de expressão e emoção que muitas vezes por timidez, vergonha, acabamos deixando de lado. Foi muito bom pois nos ajuda ampliar nosso olhar pedagógico e pessoal também”; "O encontro foi muito bom, exercitando todo o corpo, com técnicas de alongamentos e respiração, um momento de encontro consigo mesmo, de sentir o corpo; um segundo momento com jogos cênicos, envolvendo vários sentimentos, emoções, expressões faciais, com técnicas também bem divertida. Foi maravilhosa a tarde e enriquecendo ainda mais nossas experiências, nossas vivências, deixando a vergonha de lado".

Cabe esclarecer que a oficina foi desenvolvida na FURB, em laboratório adequado de artes cênicas com 3 (três) horas de duração. A ambientação em uma sala específica por si só já oferece ao praticante novas possibilidades. A sala não possui carteiras, o chão apresenta piso apropriado de madeira e uma parede de espelhos. Os então "professores alunos”, conforme já 
mencionado, são convidados a alongar o corpo e treinar a respiração ao som de músicas calmas e que habitualmente não tocam na mídia. As atividades são desenvolvidas inicialmente no coletivo e posteriormente em grupos e duplas.

A sensibilização corporal entra em cena oferecendo um enlace com a música e o corpo no espaço como se observa nos depoimentos: “Adorei, acrescenta muito. Descobri como pode ser tão agradável trabalhar com músicas tão calmas. Nós precisamos destes momentos mais calmos"; "A formação de hoje foi bastante produtiva, pois, trabalhou a relação entre o corpo e movimento, além da expressividade. Ambos os movimentos pode-se trabalhar com a expressão e a música utilizada influencia diretamente nesse trabalho".

Após a compreensão de que o corpo, a sensibilidade e a criatividade constituem a ferramenta de trabalho da oficina novos desafios são propostos. É oferecido para o grupo um grande pedaço de papel pardo e com o mesmo são desenvolvidas várias dinâmicas. O papel serve para fazer som, inventar formas, contar histórias. E novas descobertas emergem: "Foi muito proveitosa à oficina, principalmente o momento em que tivemos que no coletivo segurar o papel. Para mim foi novidade o som que saiu dele. Gostei também de fazer o "teatro"com mímica. Com certeza levarei para sala de aula”.

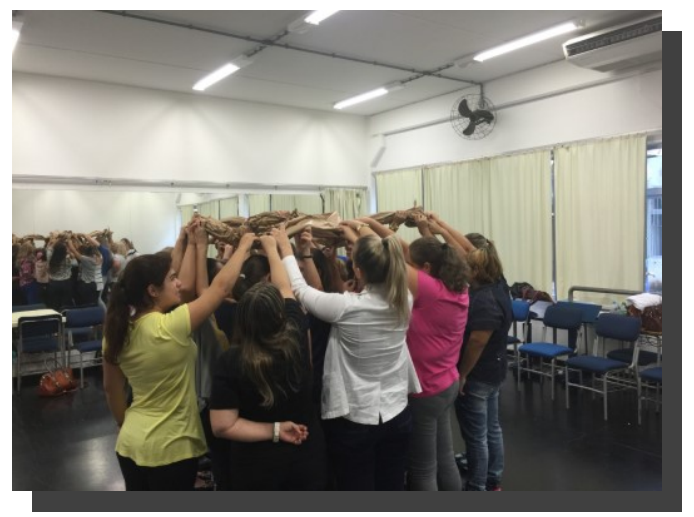

Imagem 1: Atividades com o papel produzindo som e forma.

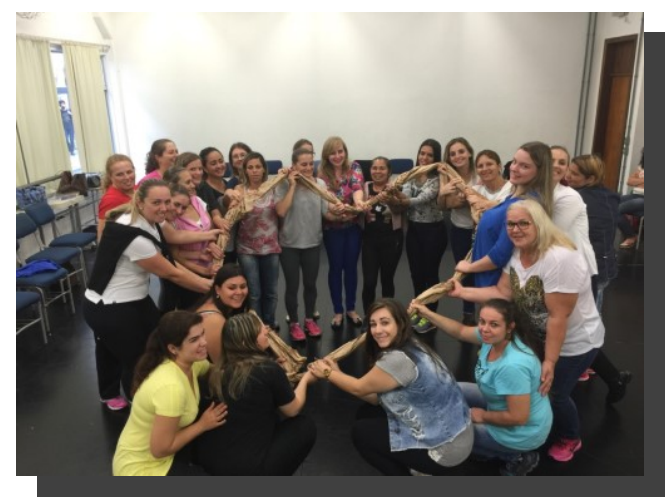

Imagem 2: Atividades com o papel produzindo forma e significado. 
O papel também oferece a possibilidade de reflexão. Os envolvidos são convidados a desenhar, pintar, escrever no papel a cerca do que a oficina lhes oferece. Assim sendo, emoção, ponderação e imaginação surgem a cena de forma imbricada. Após deixarem suas impressões no papel todos os envolvidos são convidados a retornar ao movimento dançando ao redor do papel e simultaneamente visualizarem o que nele está posto. Tal dinâmica oferece possiblidade aos participantes de conhecerem também o pensamento e o imaginário de seus colegas de oficina e como a mesma os afetou.

O papel então se torna um protocolo constituído de emoção e sensações. As Artes Visuais interagem uma vez que se percebe a presença de muitos desenhos. Poesias e palavras transparecem de maneira bastante reflexiva onde as palavras "prazer", "paz" "corpo", "consciência" e "história" aparecem de forma recorrente. Esse modo um tanto lúdico e criativo de protocolo contribui para que os integrantes das oficinas revelem seus pontos de vista, promovendo sobremaneira a avaliação individual e em grupo sobre o processo de ensino e aprendizagem, permitindo verificar o que os participantes aprenderam com as oficinas.

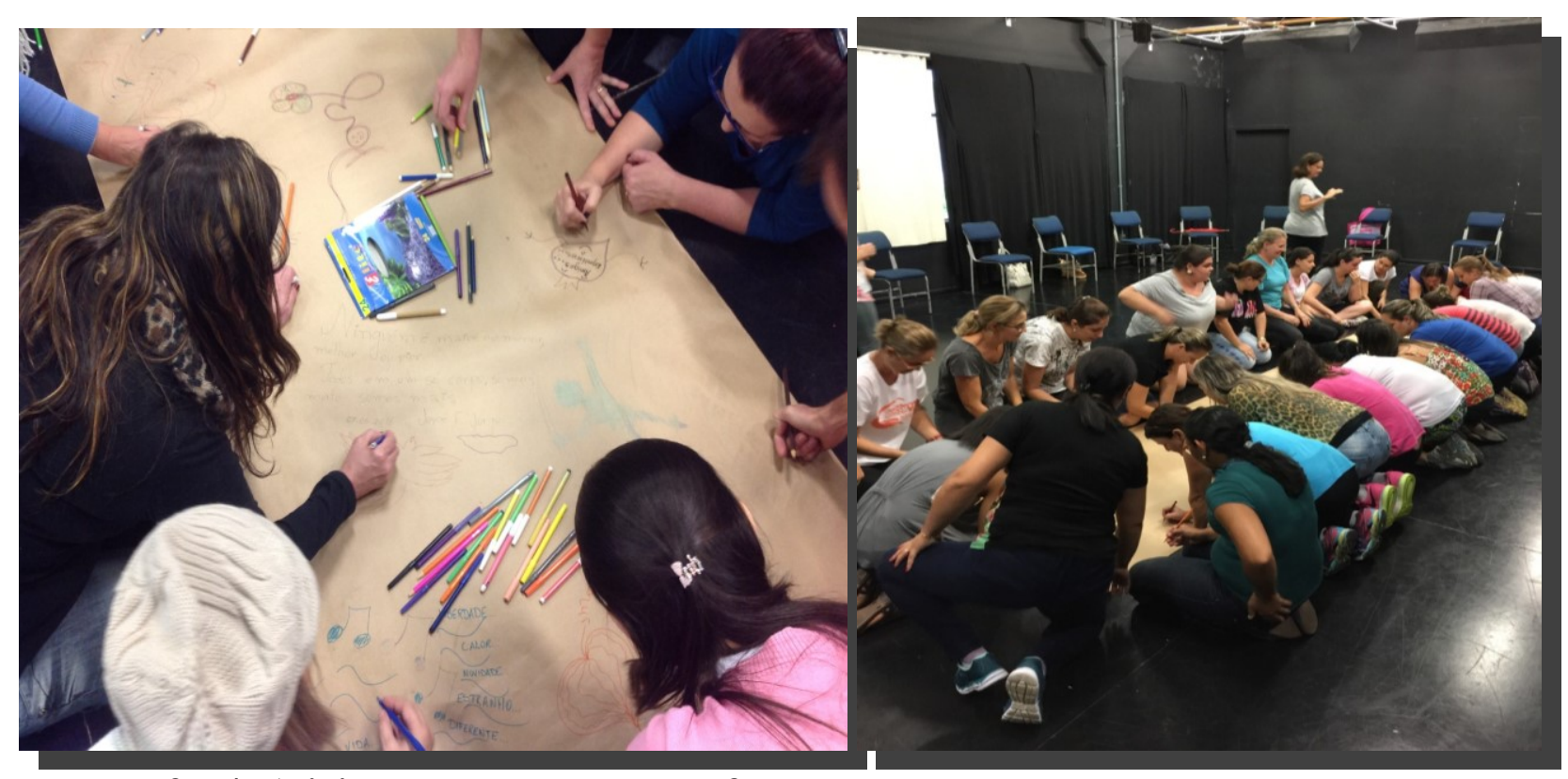

Imagem 3 e 4: Atividades com o papel em forma de protocolo.

Após tal atividade, os "alunos" já ambientados com o espaço cênico e mais conscientes de seu corpo e do que podem fazer com o mesmo são divididos em grupos e encorajados a criar e representar uma história para ser contada apenas com a utilização do corpo, sem fazer uso da voz. Surgem representações de histórias infantis já conhecidas e de domínio público como outras totalmente inéditas. 


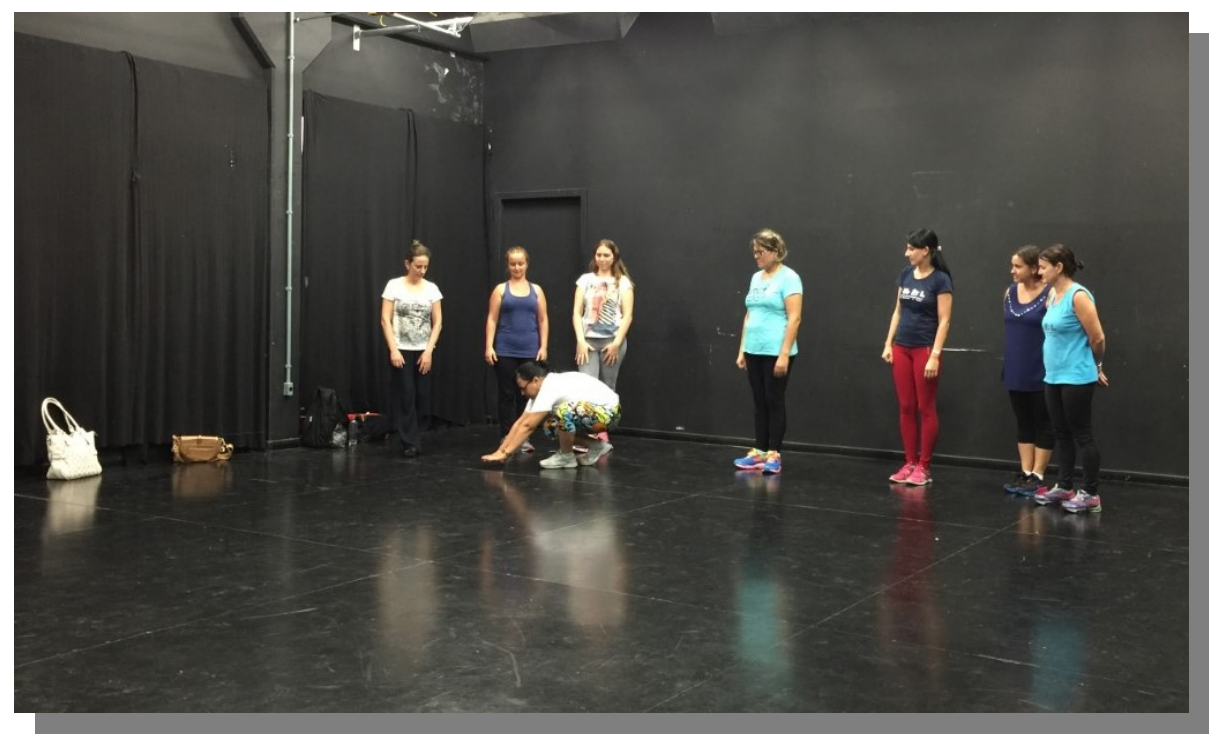

\section{Imagem 5: Apresentação de cenas das histórias.}

Ainda como forma de avaliação, ao final do encontro cada participante escreve em um papel as suas impressões sobre a oficina e fragmentos dos depoimentos encontram-se permeados no estudo: "Tarde prazerosa onde pude realizar atividades utilizando o movimento e expressividade para expressar, ações, movimentos e recontar histórias, cenas e fatos de maneira mais lúdica e prazerosa"; " Foi uma tarde prazerosa onde podemos buscar mais conhecimento sobre nosso corpo e os movimentos e expressões a fim de deixar a timidez de lado, para podermos nos expressar melhor em sala com nossos alunos. Na elaboração do teatro somente com expressões também foi proveitoso pois podemos nos expressar para compor os personagens, sendo que isto pode e deve ser levado para sala de aula"; "Consegui refletir um pouco sobre as etapas que precisamos fazer com os alunos para chegar no resultado final. Principalmente no teatro, pois percebo dificuldade nas pessoas em soltar-se”. Dessa forma, foi possível conhecer o ponto de vista de cada participante sobre o que foi trabalhado. Entende-se que "[...] escrever [...] passa também a fazer parte do jogo" (LEITE, 2009, p. 300).

\section{ALGUMAS CONSIDERAÇÕES}

O texto ora aqui exposto teve como pressuposto discutir a formação do professor em experimento prático com a área das artes cênicas. Partindo das dimensões artísticas e criativas, busca-se pensar formas de interagir com o movimento e a expressividade. Para tanto, é ponto de partida a participação prática e efetiva dos envolvidos, ou seja, os "professores" no papel de "alunos". 
Percebe-se que vários mecanismos são acionados para a compreensão e construção do movimento como forma de expressividade. A vivência de jogos teatrais e oficinas que trabalham com a dança e o movimento oferecem uma formação prazerosa para os professores que participam do projeto.

A possibilidade de ter acesso ao aprendizado dentro da área das artes cênicas abarca a trajetória individual de cada qual que perpassa diversos capitais como o econômico, escolar, cultural, social e simbólico envolvendo o estilo de vida. O projeto "O jogo teatral na escola" oferece novas possibilidades para os professores e os mesmos podem adaptar e repassar o conhecimento para seus alunos. Tal intenção é percebida nos depoimentos, bem como, entendese que a formação continuada do professor torna-se imprescindível, sempre aberto a novas demandas e leis.

Participar de atividades artísticas e culturais, onde a pessoa precisa interagir e se expor não é algo que nasce espontaneamente, é instalado, inculcado por intermédio de várias ações e mobilizações que podem germinar na família e se fortalecer nas instituições de ensino, ou seja, na escola. E para tal os professores necessitam estar habilitados a fim de receber a demanda. A inculcação das atividades artísticas e sua interdependência com as diversas mobilizações, como por exemplo, a formação continuada dos professores se constrói no decorrer do tempo, ou seja, estão em jogo o antes (a bagagem pessoal de cada professor), as condições de origem (o envolvimento prévio com a área das artes cênicas) e os objetivos que almeja alcançar. Pretendese que a atividade vivenciada não seja estanque e que cada professor reverbere em suas atividades em sala de aula buscando o incremento educacional e irradiando o conhecimento para seus alunos que compreendem o público indireto do estudo.

As oficinas são ministradas de forma que possam ser facilmente transpostas para o espaço escolar onde os professores exercem sua atividade profissional, utilizando materiais de baixo custo e fácil acesso. No caso da oficina detalhada no artigo utilizou-se o papel. Em oficinas anteriores foram utilizados balões, garrafas pet, tules, dentre outros. Tais materiais tornam-se "elementos cênicos" que ajudam a quebrar as barreiras da timidez e despertar a criatividade possibilitando formas de interação entre os participantes e as ações praticadas.

Para estimular continuamente os professores no processo de inculcação das disposições artísticas conta-se ainda com a ferramenta Facebook onde o projeto "O jogo teatral na escola" possui uma página: https://www.facebook.com/jogoteatralnaescola . Assim sendo, de maneira virtual, também existe um público atingido. O Programa Institucional Arte na Escola (PIAE) também possui uma página no Facebook onde igualmente é disponibilizado material e ideias para os professores. 
Outro fato interessante é a formação de páginas de grupos fechados no Facebook, como, por exemplo, a troca de experiências que se percebe entre os professores de Indaial com a utilização de tal ferramenta. Os participantes veiculam informações sobre suas ações práticas nas escolas onde atuam que reverberam das oficinas em que participaram.

Quanto aos depoimentos, de maneira geral percebem-se relatos que trouxeram a tona sensações como o prazer, a percepção, o conhecimento, o companheirismo, a timidez, a diversão, a interação, a liberdade, a criatividade, o descobrimento do movimento individual e do trabalho em grupo. Tais sensações reverberam a favor das dimensões artísticas na construção do cidadão crítico e reflexivo.

Libertar o corpo de sua submissão, descobrir novas formas de comunicação parece ser o sentido do projeto que trata do jogo cênico. O movimento nasce assim, sob o signo da ruptura. $\mathrm{Na}$ medida em que o praticante ganha autonomia sobre seu próprio corpo e entende como o mesmo pode interagir e portar-se no espaço, ele passa não só a permitir a exploração do novo, como promover composições cênicas. Ou seja, contar histórias por intermédio do movimento.

Aquilo que escapa à percepção anterior a oficina passa a conectar-se e fazer sentido irradiando da infinidade de pequenas sensações como revelaram os depoimentos dos professores em questão. O intangível torna-se tangível em dança, movimento, forma e história.

E a história quando materializada no corpo em movimento torna-se viva, o "expressarse" emerge como ação de selecionar o material criativo produzindo informações e trocas com o ambiente. A organização corporal realça então novas correlações artísticas e expressivas. Concorda-se que o corpo que cria aprende e tal aprendizado se conquista criando. É o jogo cênico em cena onde não acontece uma transferência linear de informação e sim novos acordos práticos entre o corpo, a expressividade e o ambiente.

\section{NOTAS}

1 "O objetivo do projeto [Formação Continuada] é qualificar professores de arte na educação infantil, ensino fundamental, médio e superior, com ações sistemáticas que proporcionem aprendizagem efetiva em arte e seu ensino, e subsidia a reflexão de práticas e processos educacionais" (SCHRAMM; CABRAL, 2010, p. $30)$.

2“O projeto Midiateca, atualmente conta com aproximadamente 7.500 materiais educativos no acervo. Destaca a importância do uso desses materiais no processo ensino-aprendizagem de Artes Visuais, Música, Dança e Teatro. Focaliza a utilização de materiais de arte, como produto artístico, cultural, social e histórico" (SCHRAMM; CABRAL, 2010, p. 32).

\section{REFERÊNCIAS}

BOURDIEU, Pierre; Alain, DARBEL. O amor pela arte: os museus de arte na Europa e seu público. São Paulo: Editora da Universidade de São Paulo: Zouk, 2003. 
BOURDIEU, Pierre. Coisas Ditas. São Paulo: Brasiliense, 2004. 234 p.

. Os três estados do capital cultural. In: NOGUEIRA, Maria Alice; CATANI, Afrânio

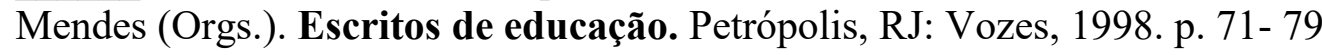

KOUDELA, Ingrid Dormien. Jogos Teatrais. - 4. ed. - São Paulo: Perspectiva, ${ }^{1} 998$.

LEITE, Vilma Campos dos Santos. Jogo teatral e a criação literária. In: FLORENTINO, Adilson; TELLES, Narciso (orgs.). Cartografias do ensino do teatro. Uberlândia: EDUFU, 2009.

RYNGAERT, Jean-Pierre. Jogar, representar: práticas dramáticas e formação. São Paulo: Cosac Naify, 2009.

SCHRAMM, Marilene de Lima Körting; CABRAL, Rozenei Maria Wilvert. Arte na Escola: um olhar sobre a história, limites e desafios da formação continuada e midiateca. In: SILVA, Neide de Melo Aguiar; RAUSCH, Rita Buzzi (orgs.). Extensão universitária: movimentos de aproximação entre sociedade e universidade. Blumenau: Edifurb, 2010.

SPOLIN, Viola. Jogos teatrais na sala de aula: um manual para o professor. São Paulo: Perspectiva, 2008.

MARQUES, Isabel. Dançando na escola. 3 ed. São Paulo: Cortez, 2006. 